\title{
EFFECT OF HEAT TREATMENT ON MECHANICAL PROPERTIES AND RESIDUAL STRESSES IN ADDITIVELY MANUFACTURED PARTS
}

\author{
O. Vaverka*, D. Koutný ${ }^{*}$, R. Vrána ${ }^{*}$, L. Pantělejev ${ }^{* *}$, D. Paloušek ${ }^{*}$
}

\begin{abstract}
Heat treatments commonly used for post-processing in additive manufacturing (AM) deal with relieving residual stresses. However, generally these treatments reduce strength properties of the material such as yield stress (YS) or ultimate tensile strength (UTS). This paper is aimed at finding the optimal heat treatment for additively manufactured parts made of aluminum alloy AlSi10Mg. Different heat treatments are compared. The positive effect of solution treatment with quenching and artificial aging on strength properties with simultaneous induction of compressive residual stress in the top surface of specimens is shown.
\end{abstract}

Keywords: residual stress, mechanical properties, heat treatment, Selective Laser Melting, AlSi10Mg

\section{Introduction}

Additive manufacturing of metals brings new possibilities in many industrial applications. Advantages such as design freedom, integration of multiple components, optimally distributed material together with mechanical properties comparable or outperforming the properties of conventionally manufactured materials are very beneficial in automotive, aeronautics or space industry. The most widespread of metal AM technologies is Selective Laser Melting (SLM). The process is layer based, wherein each layer a fine metal powder is spread over the build area and melted by laser in regions given by part cross-section. By sequential repetition of process layer by layer a desired shape of the part is created. However, the melting of powder and its solidification into homogenous solid material causes the biggest disadvantage, which is residual stress. During solidification of the new layer, a stress in the previous layer is induced due to rapid cooling of the melt and change in material volume. The accumulation of stress, layer by layer, can cause component distortion or cracking of the material.

There are many methods for determining residual stress in part. Some are non-destructive such as X-ray (Mercelis et al., 2006) or neutron diffraction (Wu et al., 2014), some are destructive - hole drilling method (Casavola et al., 2009), crack compliance method (Mercelis et al., 2006), contour method (Prime, 2000) or methods based on micro-hardness indentations (Dai et al., 2017). For further analysis of this phenomenon, numerical models based on finite element method (FEM) (Van Belle et al., 2012 and Zaeh et al., 2010) were presented, which simulate the origin of residual stresses and predict the part distortion. To prevent the parts from distorting, several aspects of manufacturing were investigated. Studies on the influence of laser properties and scanning strategies (Wu et al., 2014), platform pre-heating or postprocessing heat treatments (Shiomi et al., 2004) were carried out. According to Shiomi (2004), the best way to reduce the residual stresses is the heat treatment.

Considering aluminum alloys, the yield strength (YS) and ultimate tensile strength (UTS) are generally higher when manufactured additively than conventionally (e.g. casted) (Kempen et al., 2012). However, that is valid only for material in the as-built state. When a simple post-processing heat treatment is applied (e.g. $300{ }^{\circ} \mathrm{C} / 2 \mathrm{~h}$ or $530{ }^{\circ} \mathrm{C} / 2$ 2,5h), YS and UTS decline (Rosenthal et al., 2015). Thus, the requirements for residual stress elimination and demand for high strength contradict each other. Post-

\footnotetext{
Institute of Machine and Industrial Design, Brno University of Technology, Technická 2896/2; 616 69, Brno; CZ, Ondrej.Vaverka@vut.cz

** Institute of Materials Science and Engineering, Brno University of Technology, Technická 2896/2; 616 69, Brno; CZ,
} 
processing methods were recently investigated considering only one of these aspects, thus the postprocessing, that would eliminate the residual stress and preserve the high values of YS and UTS is not known. In this paper, the comparative analysis of different heat treatments together with residual stress FEM calculation is presented.

\section{Materials and methods}

The AlSi10Mg aluminum alloy was originally developed for casting. For its good weldability and heat conductivity is used in additive manufacturing and it has become the most common aluminum alloy used for SLM. With proper process parameters, the density of SLM manufactured parts is $99.8 \%$ (Kempen et al., 2012). As was reported by Mertens et al. (2015), heat treatment has a strong, mostly negative, influence on YS and UTS, although the elongation at break generally increases.

Heat treatments for AlSi10Mg could be divided into two categories: annealing for residual stress elimination (1) and solution treatment followed by quenching and artificial aging (2). Based on paper by Mertens et al. (2015) and handbook for aluminum alloys by Michna et al. (2005), the promising heat treatments (Table 1) were chosen for comparison.

Tab. 1: Description of used heat treatments.

\begin{tabular}{lc}
\hline No. & Heat treatment parameters \\
\hline HT 1 & $300^{\circ} \mathrm{C} / 3$ hours \\
\hline HT 2 & $250{ }^{\circ} \mathrm{C} / 2$ hours \\
\hline HT 3 & $520^{\circ} \mathrm{C} / 6$ hours/ water quench $/ 175^{\circ} \mathrm{C} / 4$ hours \\
\hline HT 4 & $510^{\circ} \mathrm{C} / 0.1$ hour/ water quench $/ 170^{\circ} \mathrm{C} / 8$ hours \\
\hline HT 5 & no heat treatment (as-built)
\end{tabular}

For comparative analysis of heat treatments, the exact values of residual stresses were not needed. Therefore, the method of deformation measurement (Zaeh et al., 2010) was used in this paper. The test specimen - cantilever (Fig. 1) was cut in the middle and the deformation caused by residual stress was measured by means of optical digitalization (Fig. 2). During the SLM fabrication, two perpendicular cantilevers for residual stress investigation in $\mathrm{X}$ and $\mathrm{Y}$ direction and three tensile testing specimens (Fig. 1) were placed on building platform.

For approximate determination of the stress value, the FEM simulation was used. The FEM approach is based on the idea, used by Prime (2000), that the residual stress could be estimated by forcing the deformed surface back to its original shape; and on the study of Mercelis and Kruth (2006) where they showed, that highest tensile residual stress is located in the top surface.

In this study, a profile of the top surface was obtained from the 3D scanned shape of deformed samples and approximated by a polynomial of second order. The same polynomial function was used for creation of CAD model of the cantilever to ensure precise deformation in ANSYS Workbench. Using nodal displacement function, the boundary condition of the flat top surface of cantilever model was prescribed and residual stress on top surface was obtained. Residual stress values in Table 2 are average values from the top layer of the deformed surface. Stress in the rest of the cantilever was not considered.

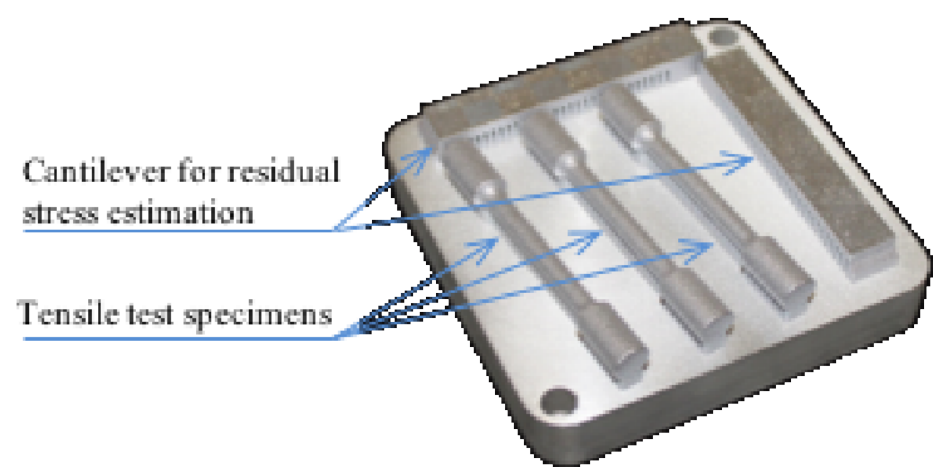

Fig. 1: Building platform with test specimens 


\section{Results and discussion}

Tensile tests were carried out with 3 specimens minimum. The average values of YS, UTS, and elongation at break are shown in Table 2. Results showed that stress relieving treatments (HT 1, HT 2) had a negative effect on YS and UTS, on the other hand, ductility was improved in comparison with the asbuilt state (HT 5). The value of YS (UTS) was only 58\% (56\%) in case of HT1 but more than 2 times higher elongation was measured. Compared to that, HT 2 affect the mechanical properties less, causing a decline of YS of $14 \%$, UTS of $25 \%$ and a simultaneous increase in elongation about $0.9 \%$ in comparison with the as-built state.

Solution treatments with quenching followed by artificial aging (HT 3, HT 4) showed a slight increase in YS values together with a significant decrease in UTS (of about $30 \%$ compared to as-built state), the ductility was slightly reduced in comparison with the as-built state. Results of specimens HT 3 and HT 4 were very similar despite the difference in holding times during solution treatment. Possible cause of this phenomenon could be fine microstructure of parts made by SLM (Kempen et al., 2012). Probably, the casted parts (HT 4 is typical for casted AlSi10Mg) require longer solution times for microstructure refinement, but SLM parts need just appropriate temperature for quenching and no further refinement of the microstructure is needed.

According to the measured deformations, the highest value of residual stress occurred in the as-built state. Using the commonly recommended heat treatment for residual stress relieving (HT 1) the smallest deformations were measured on the cantilever (Fig. 2a) however, the residual stress had still tensile character. For practical application, more beneficial for the component lifetime would be heat treatment, which would induce compressive stress in the subsurface layer. Results showed (Table 2), that this could be achieved by applying HT 3 or HT4 (Fig. 2b).

Tab. 2: Stress and deformation results of different heat treatments.

\begin{tabular}{ccccccc}
\hline No. & $\begin{array}{c}\text { YS } \\
\boldsymbol{R}_{\mathbf{p 0 , 2}}[\mathbf{M P a}]\end{array}$ & $\begin{array}{c}\text { UTS } \\
\boldsymbol{R}_{\mathbf{m}}[\mathbf{M P a}]\end{array}$ & $\begin{array}{c}\text { Elongation } \\
{[\mathbf{\%}]}\end{array}$ & $\begin{array}{c}\text { X direction } \\
{[\mathbf{m m}]}\end{array}$ & $\begin{array}{c}\text { Y direction } \\
{[\mathbf{m m}]}\end{array}$ & $\begin{array}{c}\text { R. S.* } \\
{[\mathbf{M P a}]}\end{array}$ \\
\hline HT 1 & 139 & 225 & 8.8 & +0.19 & +0.19 & +6 \\
\hline HT 2 & 204 & 303 & 4.4 & +0.52 & +0.51 & +22 \\
\hline HT 3 & 258 & 288 & 2.8 & -0.24 & -0.23 & -17 \\
\hline HT 4 & 246 & 287 & 3.2 & -0.25 & -0.23 & -17 \\
\hline HT 5 & 237 & 400 & 3.5 & +1.97 & +1.94 & +75 \\
\hline
\end{tabular}

* Residual stress, tensile (+) or compressive (-), according to FEM analysis

FEM analysis for the as-built state estimated that the stress before relieving was approximately $75 \mathrm{MPa}$ in top surface (Fig. 3), which was 30\% of YS in this case. Using the heat treatment, the stresses decreased relatively on 5\% of YS in case of HT 1 and $8 \%$ of YS in case of HT 2. The stress values were $5 \mathrm{MPa}$ and $16 \mathrm{MPa}$, respectively. The same deformations were measured for HT 3 and HT 4, thus the simulation was common for both cases and residual stress of $22 \mathrm{MPa}$ was obtained.
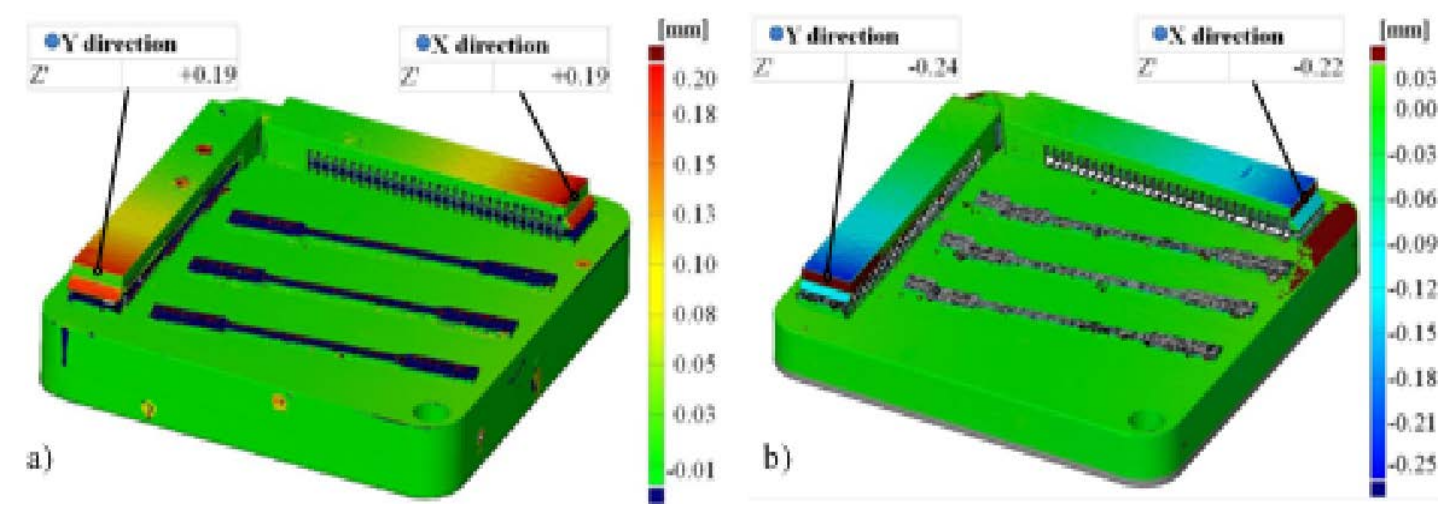

Fig. 2: a) Stress relieving heat treatment (HT 1). b) Solutioned, quenched and artificially aged (HT 3). 


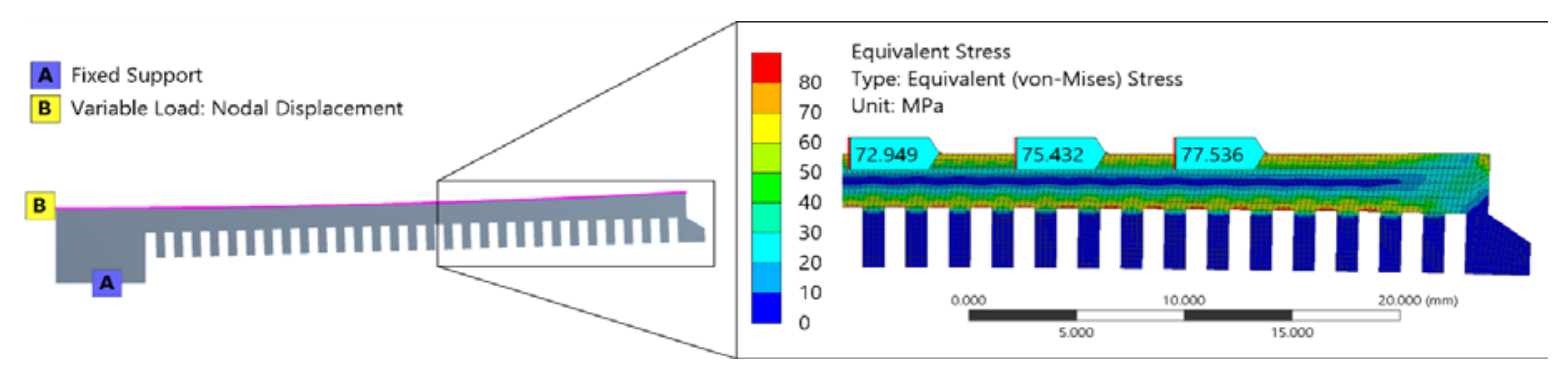

Fig. 3: Boundary conditions and Von-Mises stress in the cantilever. Relevant stress is in the top surface.

\section{Conclusions}

Four heat treatments were investigated. Two typical HT for reducing residual stress and two for maximizing strength properties of aluminum alloys. Results of all heat treatments were compared with values for the as-built state. Stress relieving treatments reduced stress in the specimen to $6 \mathrm{MPa}$ (75 MPa in the as-built state) but also rapidly decreased YS. The solution treatments caused compressive residual stress in the top layer of about $17 \mathrm{MPa}$ and additionally slight increase in YS. For practical use, HT 4 is more efficient, due to shorter solution time and it is preferred for best mechanical properties. Considering similar results from HT 3 and HT 4, holding time in HT 3 for artificial aging could be reduced and the treatment could be further improved in following research activities.

\section{Acknowledgement}

The research leading to these results has received funding from the Ministry of Education, Youth and Sports under the National Sustainability Programme I (Project LO1202) and project FSI-S-17-4144.

\section{References}

Casavola, C., Carnpanelli, S. L. and Pappalettere, C. (2009) Preliminary investigation on distribution of residual stress generated by the selective laser melting process. Journal of Strain Analysis for Engineering Design, 44, 1, pp. 93-104.

Dai, D. H., Gu, D. D., Poprawe, R. and Xia, M. J. (2017) Influence of additive multilayer feature on thermodynamics, stress and microstructure development during laser 3D printing of aluminum-based material. Science Bulletin, 62, 11, pp. 779-787.

Kempen, K., Thijs, L., Van Humbeeck, J. and Kruth, J. P. (2012) Mechanical Properties of AlSi10Mg Produced by Selective Laser Melting. Physics Procedia, 39, pp. 439-446.

Mercelis, P. and Kruth, J. P. (2006) Residual stresses in selective laser sintering and selective laser melting. Rapid Prototyping Journal, 12, 5, pp. 254-265.

Mertens, A., Dedry, O., Reuter, D., Rigo, O. and Lecomte-Beckers, J. (2015) Thermal Treatments of AlSi10Mg Processed by Laser Beam Melting, in: Proceedings of the 26th International Solid Freeform Fabrication Symposium, Dayton, OH, USA, pp. 1007-1016.

Michna, Š., Lukáč, I., Očenášek, V., Kořený, R., Drápala, J., Schneider, H., Miškufová, A. et al. (2005) Encyclopedia of aluminum. Adin, s. r. o., Prešov, ISBN 80-89041-88-4 (in Czech).

Prime, M. B. (2000) Cross-Sectional Mapping of Residual Stresses by Measuring the Surface Contour After a Cut. Journal of Engineering Materials and Technology, 123, 2, pp. 162-168.

Rosenthal, I., Tiferet, E., Ganor, M. and Stern, A. (2015) Post-processing of AM-SLM AlSi10Mg specimens: Mechanical properties and fracture behaviour. Annals of „Dunarea de Jos“ University of Galati, 26, 12, pp. 3338.

Shiomi, M., Osakada, K., Nakamura, K., Yamashita, T. and Abe, F. (2004) Residual stress within metallic model made by selective laser melting process. Cirp Annals-Manufacturing Technology, 53, 1, pp. 195-198.

Van Belle, L. Vansteenkiste, G. and Boyer, J. C. (2012) Comparisons of numerical modelling of the Selective Laser Melting. Material Forming - Esaform 2012, Pts 1 \& 2, 504-506, pp. 1067-1072.

Wu, A. S., Brown, D. W., Kumar, M., Gallegos, G. F. and King, W. E. (2014) An Experimental Investigation into Additive Manufacturing-Induced Residual Stresses in 316L Stainless Steel. Metallurgical and Materials Transactions a-Physical Metallurgy and Materials Science, 45A, 13, pp. 6260-6270.

Zaeh, M. F. and Branner, G. (2010) Investigations on residual stresses and deformations in selective laser melting. Production Engineering, 4, 1, pp. 35-45. 